Karadeniz Uluslararası Bilimsel Dergi

Volume: 53, Spring-2022, p. (21-33)

ISSN: 1308-6200 DOI Number: https://doi.org/10.17498/kdeniz.1077238

Research Article

Received: Feb 22, 2022 | Accepted: Feb 27, 2022

This article has been checked for plagiarism.

\title{
ИЛЬЯ ОКРОМЧЕДЛИШВИЛИ И АКТУАЛЬНЫЕ ВОПРОСЫ КАРТВЕЛОЛОГИИ
}

\section{İLİA OKROMÇEDLISSVILİ VE KARTVELOLOJI'NİN GÜNCEL KONULARI}

\author{
ILIA OKROMCHEDLISHVILI AND CURRENT ISSUES OF \\ KARTVELOLOGY
}

\section{Mariam KOBERIDZE*}

\begin{abstract}
АННОТАЦИЯ
Илья Окромчедлишвили является одним из видных представителей нового поколения II половины XIX века - «тергдалеулеби», который еще с Петербургского университета дружил с Ильей Чавчавадзе. Он всегда был рядом с Ильей, как ближайший друг и соратник на арене грузинской общественной жизни. После окончания армяно-грузинского отделения Петербургского университета Илья Окромчедлишвили лучшую пору своей жизни - двадцать пять лет посвятил научнопедагогической деятельности в Московском лазаревском институте восточных языков и Московском университете. В то время Москва была вторым городом царской Российской империи (после Санкт-Петербурга), в одном из высших учебных заведений которого существовала кафедра грузинского языка. Вдохновителем открытия этой кафедры являлся Илья Окромчедлишвили. Составленная им учебная программа, дошедшая до нас, дает наглядное представление об объеме обучения грузинскому языку и литературе на первом, втором и третьем курсах специальных классов. Илья Окромчедлишивили внес особый вклад в дело воспитания, обучения, содействия, материальной помощи и обеспечения талантливой передовой грузинской молодежи.

За длительный период своей деятельности в Москве он не прерывал тесную связь с родиной - занимаясь благотворительностью и оказывая материальную помощь, тем самим способствовал возрождению и развитию грузинской национальной культуры. Илья Окромчедлишвили систематически оказывал материальную помощь обществу по распространению грамотности. Следует отметить, что в сентябре 1881 года обществу по распространению грамотности среди грузин он пожертвовал 6000 рублей на издание грузинских рукописей. При финансовой помощи Ильи
\end{abstract}

\footnotetext{
* ORCID: 0000-0002-6604-1628, Prof. Dr. Gori State Teaching University, Gori, Georgia, maikoberidze@gmail.com
} 


\section{Илья Окромчедлишвили И Актуальные Вопросы Картвелологии}

Окромчедлишвили и сделанных замечаний 29 июля 1884 года в типографии Эквтиме Хеладзе в Тбилиси была напечатана «Висрамиани» (редакторы: Илья Чавчавадзе, Александре Сараджишвили, Петр Умикашвили).

Илья Окромчедлишвили занимался и архивной работой. Об этом свидетельствует личное письмо к Илье Чавчавадзе из Вены, датированное 10 сентября 1882 года, в котором он пишет, что в результате неустанной работы в московском архиве обнаружил один старый вариант «Витязя в тигровой шкуре» с миниаторами и исторические материалы, касающиеся Грузии последних двух столетий. Из Москвы Илья Окромчедлишвили Илье Чкония выслал пятый вариант рукописи «Килила и Дамана», который похож на первый вариант рукописи.

8-21 сентября 1881 года в Тбилиси был проведен пятый археологический съезд. Илья Окромчедлишвили прочитал на этом съезде доклад «Об изобретении грузинского алфавита». Эта работа Ильи Окромчедлишвили имела важный отклик в грузинской исторической науке того времени.

Изучение материалов, отражающих научную и общественную деятельность Ильи Окромчедлишвили, имеет особое значение в связи с современностью.

Ключевые слова: Илья Окромчедлишвили, Картвелология, Грузинская культура, Грузинские рукописи, грузинский алфавит, Популяризация.

\section{ÖZ}

İlia Okromçedlişvili “Tergdaleulebi” denen ve XIX. Y.Y. II. Yarısında faaliyet gösteren yeni bir kuşağın ileri gelen temsilcisidir. Petersburg Üniversitesi'nde okurken İlia Çavçavadze ile arkadaşıık yapmıştır. Gürcü kamusal yaşam arenasında en yakın arkadaşı ve meslektaşı olarak her zaman İlia'nın yanında yer almıştır. Petersburg Üniversitesi Ermenice ve Gürcüce bölümünden mezun olmuştur. Ilia Okromçedlişvili hayatının yirmi beş yılını Moskova Lazarev Doğu Dilleri Enstitüsü ile Moskova Üniversitesi'ndeki bilimsel ve pedagojik faaliyetleri üzerinde çalışarak geçirmiştir. Moskova'nın bir üniversitesinde Gürcü Dili kürsüsü vardır. Bu bölümün açılması için Ilia Okromçedlişvili fazlasıyla katkı sağlamıştır. Söz konusu kişi tarafından hazırlanan ve bize ulaşan birinci, ikinci ve üçüncü özel sınıflarda kullanılan müfredat Gürcü dili ve edebiyatı öğretiminin hacmi hakkında net bir fikir vermektedir. Ilia Okromçedlişivili, yetenekli Gürcü gençlerinin yetiştirilmesine, eğitimine, maddi yardım ve eğitim almaları noktasında özel çabalar sarfetmiştir.

Moskova'da olduğu yıllarda, anavatanıyla ilişkisini kesmemiş - hayır işleriyle uğraşarak ve maddi yardım sağlayarak, Gürcü ulusal kültürünün yeniden canlanmasına ve gelişmesine emek vermiştir. Ilia Okromçedlişvili, “Gürcüler Arasında Okuryazarlık Yayma Birliği”"ne sistematik olarak maddi yardım sağlamıştır. Eylül 1881'de Gürcü el yazmalarının basılması için söz $\quad$ konusu $\quad$ Birliğe $6.000 \quad$ ruble bağışladığı da belirtilmelidir. İlia Okromçedlişvili'nin maddi desteği ve yazdığı önsöz ile 29 Temmuz 1884'te Tiflis'te Ekvtime Kheladze Matbaasında "Visramiani" adlı eser basılmıştır (editörler: Ilia Çavçavadze, Aleksandre Sarajişvili, Petre Umikaşvili).

İlia Okromçedlişvili arşiv çalışmalarıyla da ilgilenmiştir. Bunu 10 Eylül 1882'de Viana'dan İlia Çavçavadze'ye gönderdiği mektubundan anllyoruz. Mektupta Moskova arşivlerinde yaptığı bir çalışma sonucunda, "Kaplan Postlu Şövalye" adlı eserin minyatürleri ile eski bir kopyasını ve son iki yüzyıla ait Gürcistan tarihi ile ilgili materyalleri keşfettiğinden bahsetmektedir.

Ilia Okromçedlişvili Moskova'dan "Kilila ve Damana” (Kelile ve Dimne) adlı el yazması eserin orijinaline en yakın beşinci kopyasını Ilia Çkonia'ya göndermiştir. 
8-21 Eylül 1881 tarihinde Tiflis'te beşinci arkeoloji kongresi düzenlenmiştir. İlia Okromçedlişvili bu kongrede "Gürcü Alfabesi'nin İcadı Üzerine" başlıklı bir sunum yapmıştır. İlia Okromçedlişvili'nin bu çalışması o zamanın Gürcü tarihi çalışmaları alanında biliminde önemli bir karşılık bulduğu söylenebilir.

İlia Okromçedlişvili'nin bilimsel ve sosyal faaliyetlerini yansıtan materyallerin incelenmesi günümüz hayatı ile bağlantılı olarak özellikle önem arzetmektedir.

Anahtar kelimeler: İlia Okromçedlişvili, Kartveloloji, Gürcü kültürü, Gürcü el yazmaları, Gürcü alfabesi, Hayırseverlik.

\section{ABSTRACT}

Ilia Okromchedlishvili is one of the prominent representatives of the new generation of the second half of the XIX century - "Tergdaleulebi", who was still friends with Ilia Chavchavadze from the University of St. Petersburg. He always stood by Ilia's side as a close friend and comrade in the arena of Georgian public life.Ilia Okromchedlishvili devoted the best period of his life - twenty-five years after graduating from the ArmenianGeorgian department of St. Petersburg University - to the Lazarev Institute of Oriental Languages in Moscow and pedagogical-scientific activity at the Moscow University. At that time Moscow was the second city of Tsarist Russian Empire (after St. Petersburg), in one of the higher education institutions there was a Georgian language department. The encourager of this department was Ilia Okromchedlishvili. The curriculum developed by him, which has reached us, gives us a clear idea of the scope of teaching Georgian language and literature in the first, second and third course of special classes of the Lazarev Institute. Ilia Okromchedlishvili has a special contribution to the education and training of talented progressive-minded Georgian youth, to support them, provide material assistance and support.

During his long career in Moscow, he did not lose close ties with his homeland, and contributed to the revival and development of Georgian national culture through his charity and material assistance. Ilia Okromchedlishvili systematically helped the Society for Spreading Literacy from Moscow. It is also noteworthy that in September 1881, he donated 6,000 manats to the Society for Spreading Literacy among Georgians for the publication of Georgian manuscripts. In 1884 Visramiani was published with his financial help and remarks in Tbilisi (Editors: Ilia Chavchavadze, Aleksandre Sarajishvili, Petre Umikashvili). Ilia Okromchedlishvili was also engaged in archival work. A personal letter written to Ilia Chavchavadze, dated September 10, 1882, from the city of Vienna, informs us that after two months of tireless work he found an old copy of "The Knight in the Panther's Skin" with miniatures and historical materials of the last two centuries of Georgia in the Moscow archives. He sent Ilia Chkonia the fifth version of the manuscript "Kilila and Damana" from Moscow, which looks like the first version of the manuscript.

The Fifth Archaeological Congress was held in Tbilisi on September 8-21, 1881. Ilia Okromchedlishvili's speech at this congress, "Who Invented the Georgian Alphabet", found an important echo in Georgian historical science at that time.

The study of materials reflecting the scientific and public activities of Ilia Okromchedlishvili is of special importance in relation to the present.

Key words: Ilia Okromchedlishvili, Kartvelology, Georgian culture, Georgian manuscripts, Georgian alphabet, Popularization.

\section{Введение}




\section{Илья Окромчедлишвили И Актуальные Вопросы Картвелологии}

В настоящей статье проанализирована заслуга и вклад в картвелологию представителя «тергдалеулеби» 60-ых годов XIX столетия, профессора Московского лазаревского инстутута Ильи Окромчедлишвили. Исследование явлений, хронологически удаленных во времени и пространстве, основывается на научные публикации, на архивные материалы и материалы прессы. Об его деятельности значительную информацию дает материалы личного дела Ильи Окромчедлишвили, обнаруженные в архивах Москвы и Ленинграда, которые были привезены в Грузию профессором Шалвой Гозалишвили и хранятся в Национальном центре рукописей (gozalishvili, 1976: 4-157).

\section{Методы}

При работе над научным трудом использовали историкосравнительный и описательный методы. Исходя из целей исследования был использован диахронический и синхронный анализ: хронологическое деление исследумого вопроса и его оценка по отношению к настоящему для получения окончательного итога.

\section{Итоги}

Хронологически рассмотрена общественно-педагогическая и научная деятельность Ильи Окромчедлишвили. В частности, в деле поддержки грузинского языка, литературы и истории, сбора грузинских рукописей и архивных материалов и их издания, возрождения грузинского театра, прогрессивногоразвития грузинской общественной мысли, популяризации грузинской культуры, материальной поддержки обучающихся за границей грузинских студентов.

\section{Дискуссия}

Особенный вклад в картвелолгию принадлежит профессору Московского лазаревского инстутута Илье Окромчедлишвили.Важную информацию о деятельности Ильи Окромчедлишвили дают материалы фонда исторического архива Ленинградской и Московской области, в которых собраны архивные документы, отражающие его 25-летнюю служебную и общественную деятельность, датированные 1883-1889 годами. В деле более 100 документов: диплом университета со степенью кандидата, служебная переписка, информация о заграничных командировках, послужной список и др (gozalishvili, 1976: 10).

До настоящего времени в литературных источниках указываются разные даты рождения Ильи Окромчедлишвили (Серебрякова):1835 (Хаханов, 1903:116);1936 (medzvelia, 1959:257; mushkudiani, 1971: 128); 24 апреля 1838 (gozalishvilli, 1976: 12). В архивных документах - в дипломе, послужном списке и других датой рождения указан 1838 год ( Дело правления Лазарского Института восточных языков ф. 213, оп. Д. 192, л.2). Соответствующий русский перевод фамилии Окромчедлишвили - 
Серебряков исходит из личных семейных документов отца Ильи - Лазаря ( gozalishvili, 1976: 13).

Илья Окромчедлишвили в 1860 успешно сдал вступительные экзамены в Петербургский университет и был зачислен на армяно-грузинское отделение факультета восточных языков. К тому времени в Петербургском университете учились Илья Чавчавадзе, Акаки Церетели, Нико Гогоберидзе, Бесарион Гогоберидзе. Грузинские студенты часто собирались и обсуждали злободневные вопросы своей Родины, ее настоящее и будущее (mushkudiani, 1971: 128).

Нико Николадзе передает: «Грузинские студенты под руководством Ильи Чавчавадзе собрали значительную коллекцию старинных грузинских книг и рукописей и берегли их» (nikoladze, 1865-1868: 95).

Весной 1861 года из-за общеизвестного студенческого движения Петербургский университет был закрыт и студентов распустили. Студент четвертого курса Петербургского университета Илья Чавчавадзе покинул университет и вернулся на родину, а Илья Окромчедлишвили остался в Петербурге. По возобновлении учебы в университете, 9 марта 1862 года на основании личной просьбы его восстановили на второй курс армяногрузинского отделения факультета восточных языков (leningradis saolqo sakhelmts'po arkivis universit' is pondi 14, anats'eri 5, sakme 1713, purtseli 2-11; gozalishvili, 1976: 24).

Илья Окромчедлишвили в Петербурге испитывал большие материальные трудности. 21 февраля 1862 года он обратился к Временной комиссии университетского правления с просьбой об освобождении от платы за обучение. На основании его просьбы и свидетельства о бедности (выданного 10 февраля 1861 года в Сигнаги) по решению комиссии был полностью был освожден от платы за обучение (leningradis saolqo sakhelmts'ipo arkivis universit'is pondi 14, anats'eri 5, sakme 1713, purtseli 9 ).

Здесь же следует подчеркнуть тот факт, что тогдашнему грузинскому студенчеству большую моральную и материальную поддержку оказывал первый профессор-грузин Петербургского университета Чубинашвили Давид Иесеевич. При его материальной поддержке и под его академическим руководством Илья Окромчедлишвили преодолел все трудности студенческой жизни и продолжил работу по получению высшего образования (gozalishvili, 1976: 24).

Из архивных материалов свидетельствует, что после успешной сдачи выпускных экзаменов Илья Окромчедлишвили предъявил на факультет диссертационную работу на тему «Поход Тамерлана на Грузию». По бытующему мнению, диссертационную работу он выполнил под руководством Давида Чубинашвили. Это подтверждается сохраненным в архиве докладом, который председателю Временной комиссии университетского правления предъявил исполняющий обязанности декана факультета восточных языков, профессор Давид Чубинашвили. В докладе отмечается: «Вольнослушатель армяно-грузинского отделения факультета 


\section{Илья Окромчедлишвили И Актуальные Вопросы Картвелологии}

восточных языков Илья Окромчедлишвили наряду с успешной сдачей кандидатских экзаменов дополнительно предъявил диссертацию на тему «Поход Тамерлана на Грузию», которая признана удовлетворительной» (leningradis saolqo sakhelmts'ipo arkivis universit' is pondi 14, sakme 14745 a. , purtseli 104).

С 14 июля 1863 года Илья Окромчедлишвили был назначен исполняющим обязанности старшего преподавателя грузинского языка в Лазаревском институте (mosk'ovis saolqo sakhelmts'ipo ist'oriuli arkivi, aghmosavluri enebis lazarevis inst'it'utis pondi 213, anats'eri 2, sakme 192. purtseli 14-15).

Московский лазаревский институт восточных языков, как частное учебное заведение было основано 10 мая 1815 года представителями богатой и влиятельной фамилии армянского происхождения, проживающими в Персии, братьями Иваном Лазаревичем и Екимом Лазаревичем Лазарянами. Институт готовил служащих, говорящих на языке местного населения отдаленных областей царской России (обслуживающий персонал, переводчики). Здесь изучались восточные языки - турецкий, армянский, арабский, персидский, грузинский. По сравнению с другими языками изучению грузинского языка было отведено меньше часов (по два часа еженедельно). В Московском лазаревском институте был один подготовительный клас, семь классов гимназии и один специальный класс (трехгодичный курс). Этот специальный класс имел значение высшего учебного заведения. Специальный курс по организационному составу и учебной программе был выделен от гимназических классов. У него был свой научный совет (члены: директор, инспектор, профессора, доценты, старшие преподаватели...) (Хаханов (Хаханашвии), 1903:11; gozalishvili, 1976: 33, 36).

Благодаря большим усилиям грузинских преподавателей, работающих в Лазаревском институте восточных языков в Москве, преподавание грузинского языка было поставлено на относительно высокий уровень. В этом учебном заведении со дня его основания на протяжении длительного времени в разное время грузинский язык преподавали: духовное лицо Гургенидзе Михаил Семенович и известный представитель «тергдалеулеби» Петр Накашидзе. По ходатайству попечителя Лазаревского института с 14 июля 1863 года, исполняющим обязанности старшего преподавателя кафедры грузинского языка был назначен Илья Окромчедлишвили. Именно весной того года со степенью кандидата он окончил армяно-грузинское отделение восточных языков Петербургского университета (gozalishvili, 1976:29).

C 1 октября 1865 года Кавказским комитетом Илья Окромчедлишвили по совместительству был назначен преподавателем грузинского языка для кавказских студентов в Московском университете. С 28 августа 1871 года, когда в Лазаревском институте была основана кафедра грузинского языка, Илья Окромчедлишвили с поста старшего преподавателя был переведен исполняющим обязанности доцента, а с 1 ноября 1882 года 
одновременно был избран секретарем научного совета специальных классов института (Хаханов (Хаханашвии), 1903:11; gozalishvili, 1976: 31).

В период деятельности Ильи Окромчедлишвили обучение грузинскому языку и литературе приобрело научный характер. Студенты не только изучали грузинский язык и литературу, но и знакомились с культурой, историей Грузии, у них формировалось определенное представление о природе грузинского языка. Он важное значение придавал переводческому методу. В качестве текста перевода лектор использовал отрывки из хрестоматии Давида Чубинашвили. Он при переводе текста параллельно применял грамматический анализ. Обучал пользованию словарем при изучении грузинского языка и практиковал в переводе с русского ра грузинский язык. Илья Окромчедлишвили основным учебником признавал «Грузинскую хрестоматию» своего любимого учителя - профессора Давида Чубинашвили и его словари. (Хаханов, 1903: 11; gozalishvili, 1976: 31-41).

Илья Окромчедлишвили заслужил любовь грузинской молодежи в Москве. Он был человеком доброй души, верным сыном своего народа, всегда заботящимся о будущем благополучии родины, скромным, бескорыстным благотворителем (k’oberidze, 2021 a:166-167).

Илья Окромчедлишвили своей общественно-научной и учебновоспитательной деятельностью заслужил большой авторитет. С ним всегда считались, ценили и уважали. Помимо выполнения прямых обязанностей доцента кафедры грузинского языка, Илья Окромчедлишвили бескорыстно плодотворно работал: он был одним из членов экономического совета; секретарем Совета специальных классов (1882- 1889 г.г.); наряду с другими профессорами большой вклад внес в дело пополнения и обогащения библиотечного фонда в виде пожертвований (gozalishvili, 1976: 37-42).

Во время работы в Лазаревском институте в Москве Илья Окромчедлишвили занялся лесной промышленностью. Именно в результате этого у него появилась возможность помогать бедным грузинским студентам. За свой счет помогал многим грузинам как в России, так и в других странах (ch'avch'avadze, 1898: 1-2).

За длительный период своей деятельности в Москве он не прерывал тесную связь с родиной -занимаясь благотворительностью и оказывая материальную помощь, тем самим способствовал возрождению и развитию грузинской национальной культуры. Илья Окромчедлишвили систематически оказывал материальную помощь обществу по распространению грамотности. Следует отметить, что в сентябре 1881 года обществу по распространению грамотности среди грузин он пожертвовал 6000 рублей на издание грузинских рукописей. Об этом интересную информацию дают личные письма Ильи Чавчавадзе и Ильи Окромчедлишвили. 2 октября 1881 года Илья Чавчавадзе писал Илье Окромчедлишвили: «Общество по распространению грамотности поручил мне сообщить вам, что они приступили к подготовке к печати книги древных письменностей, а денег, как вы знаете, йохтур. Из-за этого они попросили написать тебе и спросить 


\section{Илья Окромчедлишвили И Актуальные Вопросы Картвелологии}

«сможешь ли пожертвовать». Они возлагают большие надежды и ждут от тебя содействия. Желают напечатать царя Теймураза, царя Арчила, весьма внушительные книги получатся, особенно рассказы последнего» (ch'avch'avadze, 1961: 94-95).

Этим письмом Илья Чавчавадзе сообщал Илье Окромчедлишвили о просьбе правления общества по распространению грамотности среди грузин - сможет ли он оказать денежную помощь обществу в деле издания старых древнегрузинских письменностей. О согласии и благотворительности Ильи Окромчедлишвили в ответ на эту просьбу мы узнаем из грузинской прессы. Газета «Дроеба» сообщала, что Илья Окромчедлишвили пожертвовал 600 рублей на издание книг древнегрузинских письменностей (droeba, 1881 a: 1).

Ту же информирцацию передавала и Кутаисская газета «Шрома»: «Рано или поздно наступит день, когда напечатают древние письменности. Профессор Лазаревского института Илья Окромчедлишвили на это дело пожертвовал обществу по распространению грамотности 600 туманов» (shroma, 1881:3-4).

17 марта 1882 года из Москвы Илья Окромчедлишвили сообщал Илье Чавчавадзе: «Деньги выслал на имя Григола Орбелиани. Его дом находится в караван-сарае Тамамшова. Не поленись, зайди к нему и получишь 707 рублей, из которых 700 используй на театральное дела, а 7 рублей передай редакции «Иверия» - цену этого года». Он и этим не удовлетворяется : из высланных им в конце 1882 года тысяча семисот рублей тысяча рублей, как известно, тысяча были предназначены для издания памятника древнегрузинской письменности «Висрамиани», а семьсот рублей были предназначены для нужд грузинского театра (sakartvelos khelnats'erta erovnuli tsentri, pondi 170; ch’avch'avadze, 1898, 1-2; gozalishvili, 1976: 115).

При финансовой помощи Ильи Окромчедлишвили и сделанных замечаний 29 июля 1884 года в типографии Эквтиме Хеладзе в Тбилиси была напечатана «Висрамиани» (редакторы: Илья Чавчавадзе, Александре Сараджишвили, Петр Умикашвили) (sakartvelos khelnats'erta erovnuli tsentri, pondi 170; ch'avch'avadze, 1898:1-2; gozalishvili, 1976: 144).

Общество по распространению грамотности среди грузин под руководством Ильи Чавчавадзе с особой заботой относился к изданию древнегрузинских рукописей.Важен и вклад Ильи Окромчедлишвили в этом деле. Он не жалел все свои знания и материальные возможности, прилагал все усилия, чтобы как можно больше способствовать изданию письменностей. Илья Окромчедлишвили занимался и архивной работой. Об этом свидетельствует личное письмо к Илье Чавчавадзе из Вены, датированное 10 сентября 1882 года, в котором он пишет, что в результате неустанной работы в московском архиве обнаружил один старый вариант «Витязя в тигровой шкуре» с миниаторами и исторические материалы, касающиеся Грузии последних двух столетий (gozalishvili, 1976: 88, 154). 
Из МосквыИлья Окромчедлишвили Илье Чкония выслал пятый вариант рукописи «Килила и Дамана», который похож на первый вариант рукописи (kilila da damana, 1886:4).

Согласно одному из документов, хранящемуся в Национальном архиве Грузии 2 июля 1886 года Илья Чавчавадзе в селе Сагурамо принимал грузинских деятелей: Петра Умикашвили, Илью Окромчедлишвили, Илью Цинамдзгвришвили, Илью Бахтадзе, Григола Кипшидзе, Александра Чкония, Георгия Картвелишвили, Солико и Михаила Мачабели, Дмитрия Бакрадзе, которые на этой встрече от имени общества по распространению грамотности среди грузин обсудили необходимость приобретения собственной типографии для издания грузинских книг(новая типография должна была принести и прибыль). Стоимость типографии была установлена вразмере 15 тысячрублей. Приобрести типографию обществу обещали Илья Окромчедлишвили и Георгий Картвелишвили. Ксожалениюобщество не смогло основать типографию в Тбилиси, только Кутаисское отделение смогло сделать это в 1913 году (sakartvelos khelnats'erta erovnuli tsentri, pondi 48, aghts'era 1, sakme120; khundadze ,1960: 57- 58; khitarishvili, 2015).

Помимо денежной помощи, Илья Окромчедлишвили старался содействовать изданию грузинских книг. Он высылал необходимую бумагу для их печатания или же в Москве печатал отдельные брошюры и книги (mushk'udiani, 1971: 128-131).

8-21 сентября 1881 года в Тбилиси был проведен пятый археологический съезд. Члены совета специальных классов института восточных языков (директор Кананов Г.И., профессора Н.О.Эмин и Окромчедлишвили И.Л.) активное участие приняли в подготовительной работе. Этот съезд был важным историческим явлением. На съезде с докладом выступили Дмитрий Бакрадзе, Давид Чубинашвили, Александр Цагарели, Илья Окромчедлишвили. На заседании шестого отделения памятников языка и литературы археологического съезда, на котором председательствовал Дмитрий Бакрадзе, а секретарем был профессор Александр Цагарели заслушали доклад профессора Александра Цагарели «Сведения о памятниках грузинской письменности» и доклад Ильи Окромчедлишвили «Об изобретении грузинского алфавита» (gozalishvili, 1976: 42).

В своем выступлении на банкете, устроенном в честь съезда, Илья Чавчавадзе и Акакий Церетели выразили свое грубокое уважение к великим грузинам, работающим в России (ch'avch'avadze, 1955: 113; ts'ereteli, 1960:129).

Слова благодарности на банкете выразил и Илья Окромчедлишвили: «Несмотря на то, что вот уже двадцать два года живу вдали от родины, в России, но как отметил Акакий, русские морозы не охладили мое сердце и надеюсь до самой смерти так и будет, чтобы и морально и материально помогать своей стране» (droeba, 1881 b: 1-2). 
Научный доклад Ильи Окромчедлишвили «Об изобретении грузинского алфавита» был опубликован в журнале «Иверия» в октябре того же года (okromtsedlishvili,1881: 97-112) а в 1887 году на русском языке были опубликованы турды пятого археологического съезда (Окромчедлишвили, 1887: 97-112).

Доклад сопровождается заключением: «В связи с вышеизложенным осмелимся доказать три вещи: 1. В Грузии алфавит был создан царем Фарнавазом в конце четвертого века или в начале третьего века до христианства. 2. Хуцури тот же мхедрули, только изменен и 3. Если Месроп и принимал какое-либо участие во введении алфавита хуцури, то только тем, что предпочитал писать в мхедрули вместо круглых прямыми буквами» (okromtsedlishvili,1881: 111-112).

Эта работа Ильи Окромчедлишвили имела важный отклик в грузинской исторической науке того времени. Известный историк Мосе Джанашвили в 1887 году этой работе посвятил целую серию писем в «Иверии»-«Когда и откуда ввели грузинский алфавит» (Janashvili, 1887a: 1-2; Janashvili, 1887b: 1-2; Janashvili, 1887g: 1-2 ).

Позднее Александр Хаханашвили писал: «Примерный знаток грузинского языка и литературы Илья Окромчедлишвили оставил много ценных сочинений, из которых «История введения грузинского алфавита» и «Заметки о грузинской летописи» до настоящего времени считаются образцовым исследованием. Он первым доказал, что грузинский алфавит введен давно. Он опроверг ложное представление о том, что грузинская летопись составлена людьми чужеземного племени» (iveria, 1898 : 4).

Великий историк Иване Джавахишвили высоко оценил доклады, прочитанные на Пятом археологическом конгрессе (javakhishvili, 1949: 18).

Илья Чавчавадзе на протяжении всей своей деятельности проявлял неустанную заботу о грузинском театре и не жалел сил и энергии для его развития. В этой большой и почетной грузинской общественной деятельности Илье Чавчавадзе всегда помогали и поддерживали ведущие грузинские деятели и среди них его неразлучный друг Илья Окромчедлишвили, который на укрепление грузинского театра в 1880-1881 годах выделил 1700 рублей (ch'avch'avadze, 1898:1; gozalishvili, 1976:144).

Илья Окромчедлишвили вместе с Ильей Чавчавадзе заботился о развитии и других областей культуры, в частности, о расцвете грузинской национальной живописи. Особенную заботу и материальную помощь оказывал известным грузинским художникам: Александру Беридзе, Гиго Габашвили, Мосе Тоидзе и другим, которые заложили достойный фундамент и развили грузинскую национальную живопись (ch'avch'avadze, 1961: 93102).

В сентябре 1881 года Илья Окромчедлишвили для нужд Цинамдзгвриантского сельскохозяйственного училища пожертвовал 6000 рублей (gozalishvili, 1976:144). 


\section{Mariam KOBERIDZE}

При заботе и поддержке Ильи Окромчедлишвили на арену деятельности вышел Александр Хаханашвили. Когда исполнилось 25 лет научно-общественной и педагогической деятельности Ильи Окромчедлишвили и с января 1889 он вышел на пенсию, в Московском лазаревском институте восточных языков и Московском университете на кафедре грузинского языка дело дорогого учителя продолжил Александр Хаханашвили. На основании письменной рецензии-характеристики Ильи Окромчедлишвили научный совет принял постановление: пригласить (временно, условно) Александра Хаханашвили преподавателем грузинского языка (mosk'ovis saolqo sakhelmts'ipo ist'oriuli arkivi, pondi 459, anats'eri 2, sakme 4264, purtseli 13; gozalishvili, 1976: 65; k’oberidze, 2021b: 102, 106).

Этот факт является ярким подтверждением того, что Илья Окромчедлишвили имел особое влияние на Научный совет Лазаревского института, уважали его и считались с его мнением.

После выхода на пенсию Илья Окромчедлишвили с семьей вернудся в Грузию и обосновался в Тбилиси. Он продолжил до того начатое дело лесной промышленности. Он хотел содействовать успеху и развитию родной страны, возрождив торговлю и промышленность. «Я приобрел знаниея, навыки, богатство и холчу их использовать во благо своей страны» (живопись (ch'avch'avadze, $1898: 1-2$ ).

Пламенный патриот своей страны Илья Окромчедлишвили, как лесопромышленник и здесь свой основной доход направлял на воспитание молодежи (назначал стипендии), на поддержку школ - народного образования и другие общественные дела, помогал грузинскому театру, содействовал изданию важнейших памятников грузинской письменности (словарь Давида Чубинашвили) (ch'avch'avadze, 1898 : 1-2; gozalishvili, 1976: 136).

3 января 1898 года в Тбилиси в возрасте 60 лет скончался Илья Окромчедлишвили. В траурные дни в тбилисских газетах и журналах были напечатаны посвященные ему письма, некрологи и траурные объявления. Они единогласно отмечали большой вклад, попечение и заслуги усопшего перед родиной и народом, в деле развития грузинской культуры (k’vali, 1998: 46-47; tsnobis purtseli, 1898: 2). Радеющего за благополучие и развитие родины Илью Окромчедлишвили благодарный грузинский народ похоронил в Дидубском пантеоне (gozalishvili, 176: 141).

Таким образом. Илья Окромчедлишвили является одним из видных представителей нового поколения II половины XIX века - «тергдалеулеби», который еще с Петербургского университета дружил с Ильей Чавчавадзе. Он всегда был рядом с Ильей, как ближайший друг и соратник на арене грузинской общественной жизни. После окончания армяно-грузинского отделения Петербургского университета Илья Окромчедлишвили лучшую пору своей жизни - двадцать пять лет посвятил научно-педагогической деятельности в Московском лазаревском институте восточных языков и Московском университете. В то время Москва была вторым городом 
царской Российской империи (после Санкт-Петербурга), в одном из высших учебных заведений которого существовала кафедра грузинского языка. Вдохновителем открытия этой кафедры являлся Илья Окромчедлишвили. Составленная им учебная программа, дошедшая до нас, дает наглядное представление об объеме обучения грузинскому языку и литературе на первом, втором и третьем курсах специальных классов. Илья Окромчедлишивили внес особый вклад в дело воспитания, обучения, содействия, материальной помощи и обеспечения талантливой передовой грузинской молодежи. Изучение материалов, отражающих научную и общественную деятельность Ильи Окромчедлишвили, имеет особое значение в связи с современностью.

\section{БИБЛИОГРАФИЯ}

Gozalishvili, sh., (1976). Ilia okromchedlishvili (tskhovreba da moghvaweoba), tbilisi.

Droeba (1881) a. №192, tbilisi.

Droeba (1881) b. №195, tbilisi.

IVERIA (1898). №9, tbilisi.

K'vali (1998). №3, tbilisi.

K'oberidze ， m., (2021) a. enobrivi situacia mock'ovis aghmosavluri enebis lazariant institutshi: kartveluri memkvidreoba, XXV, kutaisi.

K'oberidze , m., (2021) b. aleksandre khakhanashvili da kartvelologiis akt'ualuri sak'itkhebi: goris sakhemts'ipo sasts'avlo universit'et'is zhurnali, pilologiuri kvlevebi, III, gori.

Leningradis saolqo sakhelmts'po arkivis universit'is pondi 14, anats'eri 5, sakme 1713, purtseli 2 -11 (tkhovna dek'anis rezolutsiit).

Leningradis saolqo sakhelmts'po arkivis universit'is pondi $\mathbf{1 4}$, anats'eri 5 , sakme 1713, purtseli 9 (tkhovna). sigharibis mots'moba №361, purtseli 13.

Leningradis saolqo sakhelmts'po arkivis universit'is pondi 14, sakme 14745 a., purtseli 104 - Davit Chubinashvilis avtograpi.

Medzvelia, k., (1959). tergdaleulebi da rusetis samotsiani ts'lebis revolutsioneri moghvats'eebi , 1, tbilisi.

Mosk'ovis saolqo sakhelmts'po ist'oriuli arkivi, aghmosavluri enebis lazarevis inst'it'utis pondi №213, anats'eri 2, sakme 192, purtseli 14-15.

Mosk'ovis saolqo sakhelmts'po ist'oriuli arkivi, aghmosavluri enebis lazarevis inst'it'utis pondi №459, anats'eri 2, sakme 4264, purtseli 13.

Mushk'udiani, k., (1971). Ilia okromchedlishvilis mosagoneblad: tsisk'ari,_ № 8, tbilisi.

Nik'oladze, n., (1865-1868). rcheuli nats'erebi, t.1. mogonebani, p'ublitsisturi ts'erilebi. tbilisi.

Okromchedlishvili, I., (1881). vin moigona kartuli anbani: iveria, №10, tbilisi. Kilila da damana (1886). t'bilisi. 
Sakartvelos khelnats'erta erovnuli tsentri (khelnats'erta inst'it'ut'i), ilia ch'avch'avadzis pondi 170 .

Sakartvelos khelnats'erta erovnuli tsentri (khelnats'erta inst'it'ut'i), pondi 48, aghts'era 1 , sakme 120 .

Shroma (1881). №6, kutaisi.

Tsnobis purtseli (1898). №41, tbilisi.

Ts'ereteli, a., (1960). tkhzulebani, t'. 12, tbilisi.

Ch'avch'avadze, I., (1898). Ilia Okromchedlishvili (nek’rologi): Iveria, №2, tbilisi.

Ch'avch'avadze, I., (1955). tkhzulebani, t'. 5. tbilisi.

Ch'avch'avadze, I., (1961). khzulebani, t'. 10. tbilisi.

Janashvili, M., (1887) a. ra droidgan da saidgan shemoighes kartuli anbani (Ilia okromchedlishvilis ts'erilis gamo : vin moigona kartuli anbani): iveria , №115-118, tbilisi.

Janashvili, M., (1887) b. Ra droidgan da saidgan shemoighes kartuli anbani (Ilia okromchedlishvilis ts'erilis gamo : vin moigona kartuli anbani): iveria , №121-123, tbilisi.

Janashvili, M., (1887) g. Ra droidgan da saidgan shemoighes kartuli anbani (Ilia Okromchedlishvilis ts'erilis gamo : vin moigona kartuli anbani): iveria , №126-128. tbilisi.

Javakhishvili, i., (1949). k'artuli paleograpia. tbilisi.

Khitarishvili, k., ( 2015). damat'ebiti masalebi sakartvelos tsent'ralur arkivshi datsuli ilia ch'avch'avadzestan dak'avshirebuli skhvadaskhva sakhis istoriuli dokumentebidan: Ilia ch'avch'avadzis tskhovrebisa da shemokmedebis mat'iane-akhali t'ekst'ologiuri k'vlevebi (orenovani gamotsema). elekt'ronuli biulet'ini №2. tbilisi. http://textologi.blogspot.com/p/2.html

Khundadze , t'., (1960). kartvelta shoris ts'era-k'itkhvis gamavrtselebeli sazogadoeba (nark'vevi saarkivo masalebis mixedvit) 1879-1927, tbilisi.

Дело правления Лазарского Института восточных языков, Об. И. Д. доцента грузинского языка И. Л. Окромчедлова -Серебрякова ГИАМО, ф. 213, оп. 2, Д. 192, л.2. Свидетельство.

Окромчедлов (Окромчедлишвили) И. Л. (1887). Об изобретении грузинского алфавита: См. Труды V Археологического Сьезда в Тифлисе, 1881, под редакцией графини Уваровой. XXXIX, X, II, Москва.

Хаханов (Хаханашвии), А. (1903). Тридцатилетие Специальных Классов Лазарского Института восточных языков, Москва. 